\title{
Catalytic Isomerization of Dihydroxyacetone to Lactic Acid and Alkyl Lactates over Hierarchical Zeolites Containing Tin
}

\author{
Agnieszka Feliczak-Guzik ${ }^{1,2, *}$, Myroslav Sprynskyy ${ }^{1}$, Izabela Nowak ${ }^{2}$ \\ and Bogusław Buszewski ${ }^{1}$ \\ 1 Faculty of Chemistry, Nicolaus Copernicus University, 7 Gagarina Str., 87-100 Torun, Poland; \\ mspryn@umk.pl (M.S.); bbusz@chem.umk.pl (B.B.) \\ 2 Faculty of Chemistry, Adam Mickiewicz University, 89b Umultowska Str., 61-614 Poznan, Poland; \\ nowakiza@amu.edu.pl \\ * Correspondence: agaguzik@amu.edu.pl; Tel.: +48-61-8291749
}

Received: 18 December 2017; Accepted: 11 January 2018; Published: 17 January 2018

\begin{abstract}
Hierarchical zeolites containing tin were obtained, characterized and used in a reaction of catalytic isomerization of dihydroxyacetone (DHA) to lactic acid and alkyl lactates. These catalysts are characterized by preserved crystallinity and primary microporosity with the simultaneous existence of secondary porosity regarding mesopores, which facilitates access of large molecules of reagents to active centers. Creation of additional porosity was confirmed by $\mathrm{X}$-ray diffraction and low-temperature nitrogen adsorption/desorption studies. The reaction of dihydroxyacetone isomerization was conducted in different reaction media such as methanol, ethanol or water with the use of two heating methods: microwave radiation and conventional heating. The application of microwave radiation enabled to reduce the reaction time to $1 \mathrm{~h}$ and achieve dihydroxyacetone conversion of $>90 \%$ and high yields of the desired reaction products.
\end{abstract}

Keywords: hierarchical zeolites containing tin; alkyl lactates; lactic acid

\section{Introduction}

Controlling a structure of nanometer size is critical in order to generate nanoporous materials with new functions. These nanoporous materials appear to offer unlimited possibilities in a wide range of applications in catalysis, as absorbents, sensors, optical and photovoltaic devices or fuel cells [1-4].

Recently, there has been a growing interest among scientists in the synthesis, characteristics and application of hierarchical zeolites [5-8]. These materials, characterized by occurrence of secondary porosity (mesopores) superimposed on the primary microporous structures, constitute a class of porous materials displaying molecular sieve capacity and mesoporous materials. These materials, by combining catalytic properties of conventional zeolites with increased access and transport of reagents in additional meso- or macroporosity, constitute an effective solution to the problem of mass transport which occurs while using conventional zeolites in catalytic reactions. The occurrence of mesoor macroporosity provides substrate molecules with access to active spots located in macroporesand leads to increased reaction time and catalyst lifespan [8].

Lactic acid is an important chemical compound used for the production of polymers or solvents [9]. Additionally, this compound is a source of monomers from other compounds such as lactic acid esters, acrylic acid, 1,2-propanodiol, acetaldehyde, propionic acid, oxalic acid and biodegradable plastics-PLA (polylactic acid) so-called "green polymers" [10-14]. In industry, lactic acid is mainly obtained as a result of glucose or sucrose fermentation using microorganisms. However, this process has numerous drawbacks such as: limited efficiency of the process, control of temperature and $\mathrm{pH}$ 
in the reactor, high waste production or neutralization of lactic acid by stoichiometric amounts of alkali during fermentation process [15]. Therefore, the aim of this work was to study the ability of hierarchical zeolites modified with tin in catalytic isomerization of dihydroxyacetone (DHA) to alkyl lactates and lactic acid.

\section{Results}

Figure 1 presents diffractograms of calcined, hierarchical zeolites obtained from commercial zeolites faujasite (FAU) (zeolite Y) and BEA (zeolite $\beta$ ). The diffractograms performed in low-angle range (Figure 1a,b) recorded a peak at the angle of $2 \theta \sim 2.5$ (interplanar d-spacing $\sim 3.65 \mathrm{~nm}$ ), which confirms obtaining an additional, porous structure. In turn, diffractograms of the obtained materials in the wide-angle range confirm maintaining crystalline structure of the applied commercial zeolites FAU and BEA (Figure 1c,d).
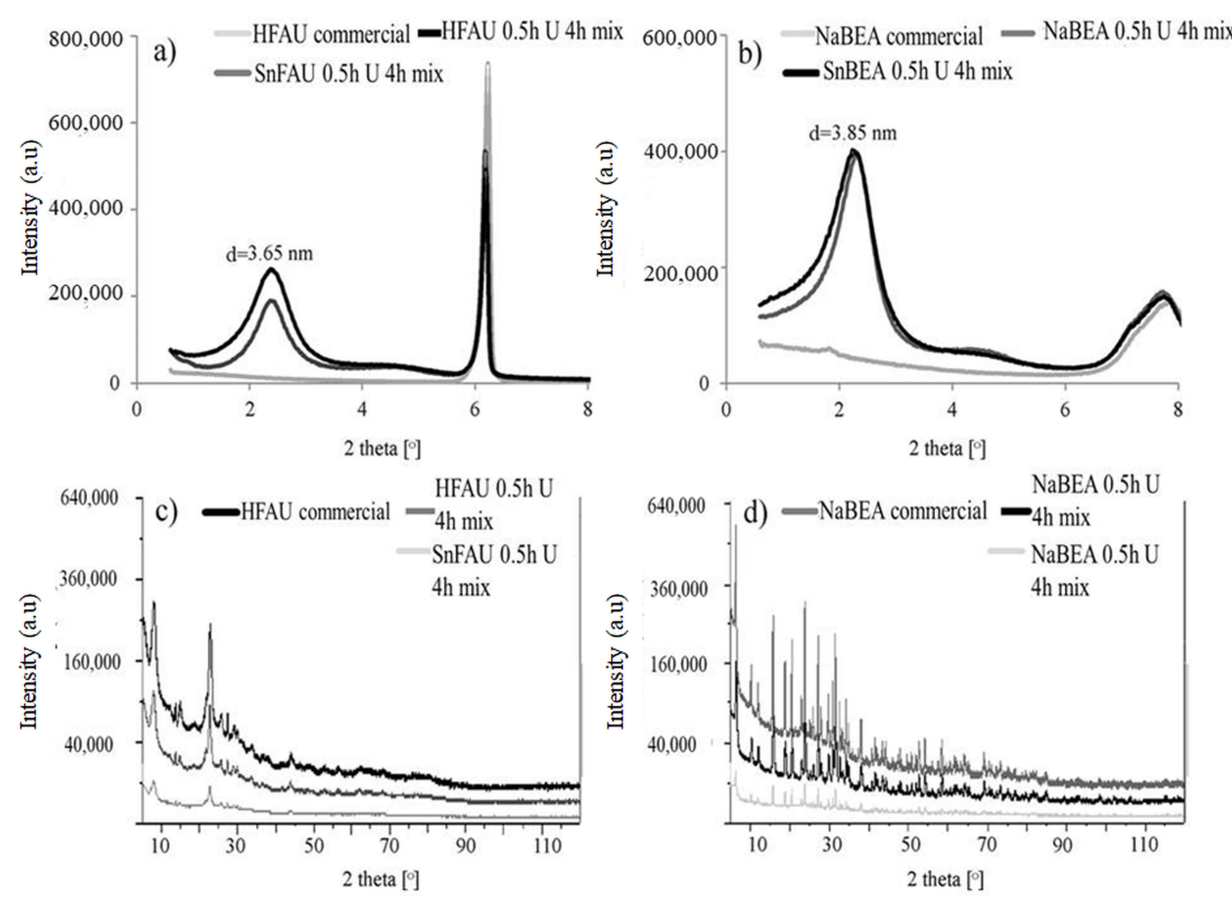

Figure 1. XRD (X-ray Diffraction) patterns of prepared hierarchical zeolites (a-d).

Zeolites are classified based on the character of tetrahedron bindings $(\mathrm{Si}, \mathrm{Al}) \mathrm{O}_{4}$ in their skeletal structure. Y zeolite is classified as faujasite (FAU) type, in which the primitive cell is built of tetragonally positioned sodalite units connected by hexagonal walls through six oxygen bridges. A characteristic feature of Beta zeolite is its polymorphic stratified crystalline structure.

Besides, zeolites are characterized by so-called cleavage, that is, ability of zeolite crystallites to crack and split along definite crystallographic structural planes called cleavage planes when subjected to pressure or impact. In our case, the occurrence of secondary porosity (mesoporosity) may be just the result of intensified cleavage resulting from modification of commercial zeolites FAU and BEA and using ultrasound processing or mixing during the synthesis of hierarchical materials [15]. A crucial role in cleavage intensification is, of course, played by the surfactants used in the modification process, which by penetrating interplanar cleavage spaces cause formation of slit mesopores.

Percentage contents of nitrogen, carbon and hydrogen obtained by using elemental analysis of the obtained hierarchical zeolites are presented in Table 1. Low percentage content of nitrogen and carbon confirms removal of the template used during the synthesis of hierarchical zeolites, such ascetyltrimethylammonium bromide (CTAB). 
Table 1. Percentage content of nitrogen, carbon and hydrogen in hierarchical zeolites.

\begin{tabular}{cccc}
\hline \multirow{2}{*}{ Materials } & \multicolumn{3}{c}{ Content (\%) } \\
\cline { 2 - 4 } & $\mathbf{N}$ & $\mathbf{C}$ & $\mathbf{H}$ \\
\hline HFAU commercial & $0.255 \pm 0.005$ & $0.151 \pm 0.004$ & $2.829 \pm 0.005$ \\
HFAU 0.5 h U 4 h mix & $0.146 \pm 0.004$ & $0.465 \pm 0,002$ & $2.606 \pm 0.005$ \\
SnFAU 0.5 h U 4 h mix & $0.199 \pm 0.004$ & $0.269 \pm 0.005$ & $2.762 \pm 0.008$ \\
NaBEA commercial & $0.273 \pm 0.006$ & $0.227 \pm 0.004$ & $1.403 \pm 0.004$ \\
NaBEA 0.5 h U 4 h mix & $0.255 \pm 0.005$ & $0.234 \pm 0.005$ & $0.711 \pm 0.002$ \\
SnBEA 0.5 h U 4 h mix & $0.199 \pm 0.004$ & $0.173 \pm 0.006$ & $1.235 \pm 0.004$ \\
\hline
\end{tabular}

Nitrogen adsorption/desorption isotherms for tin materials and commercial zeolites FAU and BEA are presented in Figures 2 and 3. Table 2 presents values of some parameters of porous structure obtained on the basis of nitrogen adsorption/desorption isotherms. The nitrogen adsorption/desorption isotherms for starting materials (1A in Figure 2 and 1B in Figure 3) are of type I (microporous materials according to IUPAC). For modified materials, a mixture of isotherms of types I and IVa (mesoporous materials according to IUPAC) was observed [16]. The obtained isotherms display both the presence of micropores connected with zeolite crystalline structure (primary porosity) and meso-/macropores (secondary porosity) formed during the modification process. Regarding the modified materials, the presence of hysteresis loop $\mathrm{H} 4$ was recorded, which is characteristic for materials containing micro-, meso-, or macropores [13]. The presence of an open-end, wider hysteresis loop at lower relative pressures also confirms the presence of pores in the meso range (2A and $3 \mathrm{~A}$ in Figure 2 and $2 \mathrm{~B}$ and $3 \mathrm{~B}$ in Figure 3). The specific surface area of the materials was established using BET (Brunauer-Emmett-Teller) and Langmuir methods. The specific surface area $S_{\text {BET }}$ and $S_{\text {Langmuir }}$ decreases in synthesized zeolites in comparison with the starting materials (commercial zeolites) and equals, respectively, $S_{\mathrm{BET}}$ from 560 to $950 \mathrm{~m}^{2} / \mathrm{g}$ and $S_{\text {Langmuir }}$ from 715 to $1240 \mathrm{~m}^{2} / \mathrm{g}$.

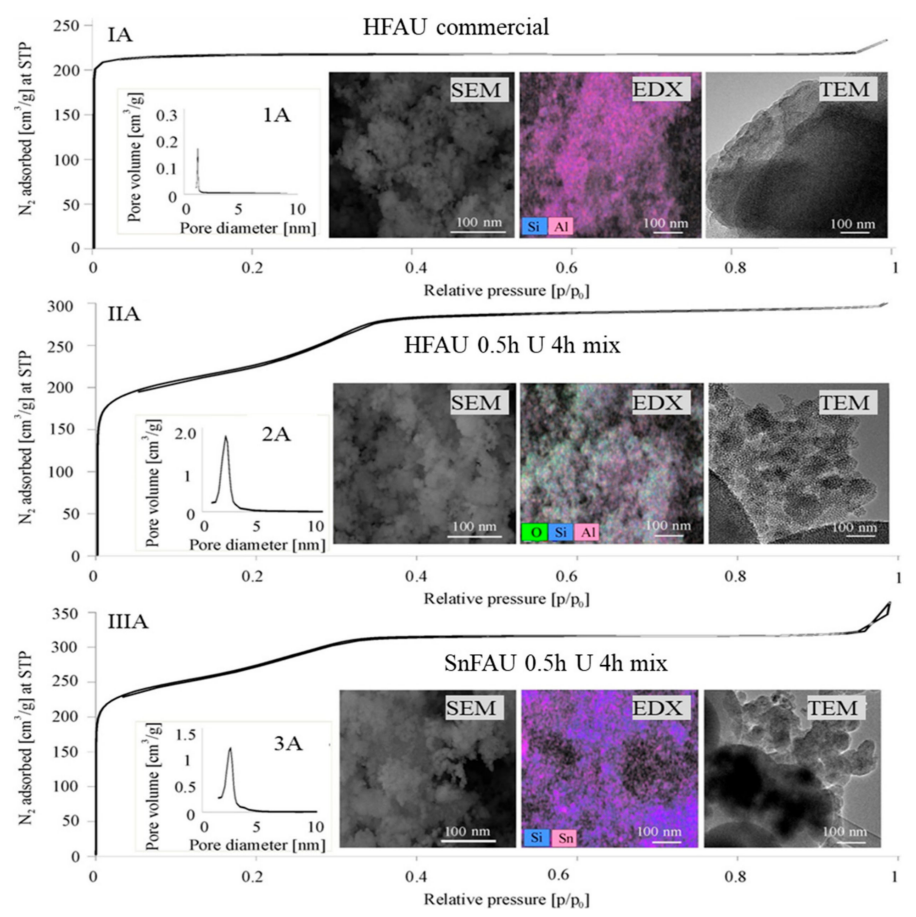

Figure 2. Isotherms of $\mathrm{N}_{2}$ adsorption/desorption for materials based on zeolite faujasite (FAU) (from IA to IIIA), pore size distribution (from 1A to 3A) and SEM, SEM/EDX (Energy-dispersive X-ray spectroscopy) and TEM images. 

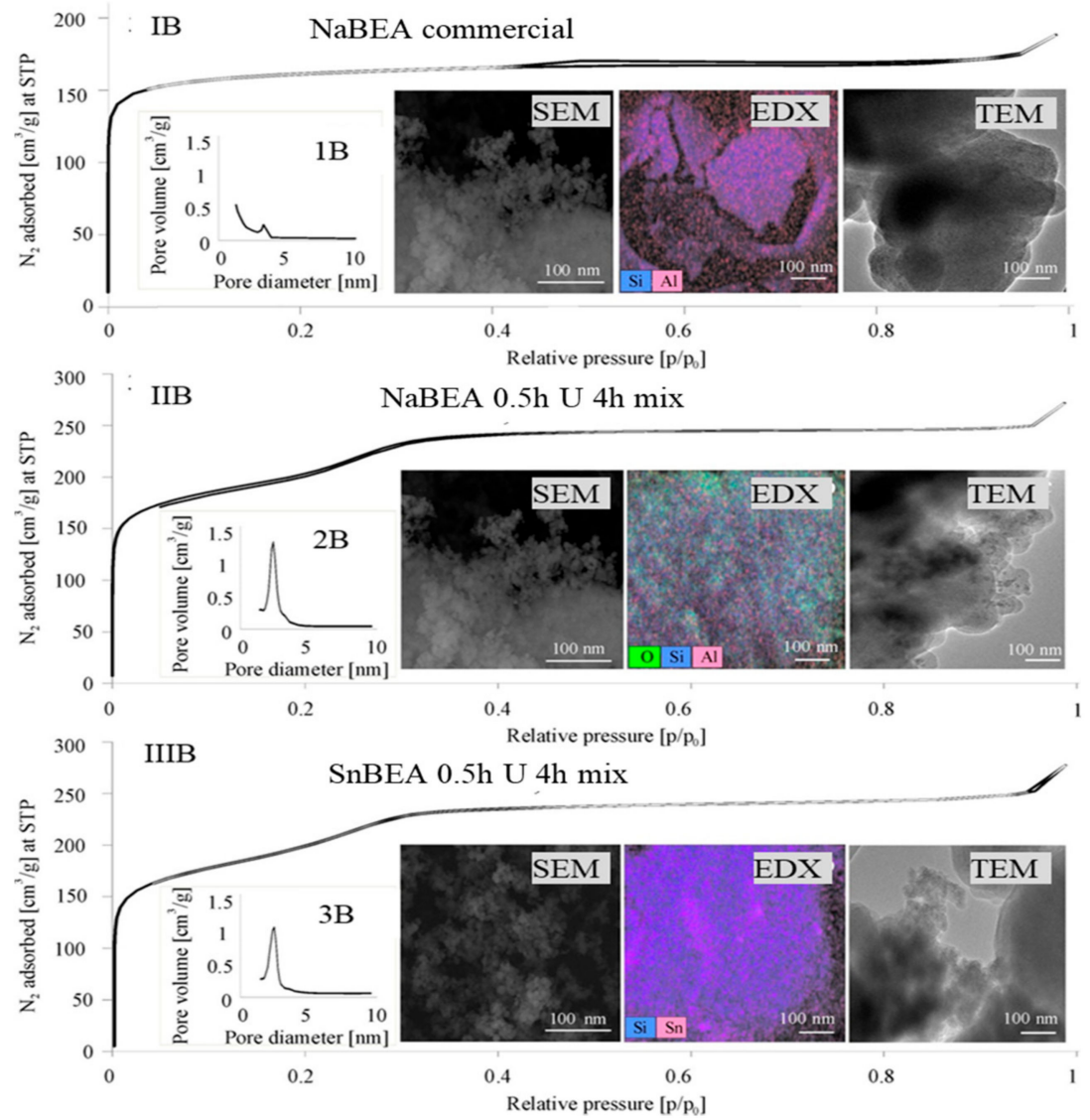

Figure 3. Isotherms of $\mathrm{N}_{2}$ adsorption/desorption for materials based on zeolite BEA (from IB to IIIB), distribution of pore size (from 1B to 3B) and scanning electron microscope (SEM), SEM/EDX and transmission electron microscopy (TEM) images.

Table 2. Porous structure parameters of synthesized hierarchical zeolites.

\begin{tabular}{|c|c|c|c|c|c|c|}
\hline \multirow{2}{*}{ Materials } & \multicolumn{4}{|c|}{ Specific Surface Area $\left(\mathrm{m}^{2} / \mathrm{g}\right)$} & \multirow{2}{*}{$\begin{array}{c}\text { Pore } \\
\text { Volume, } \\
\text { BJH }\left(\mathrm{cm}^{3} / \mathrm{g}\right)\end{array}$} & \multirow{2}{*}{$\begin{array}{c}\text { Average } \\
\text { Submesopore * } \\
\text { Size }(\mathrm{nm})>2 \mathrm{~nm}\end{array}$} \\
\hline & $S_{\text {BET }}$ & $S_{\text {Langmuir }}$ & $S_{\text {micro }}$ t-Plot & $S_{\text {ext }}$ t-Plot & & \\
\hline HFAU commercial & 718 & 972 & 946 & 26 & 0.05 & Absent \\
\hline HFAU 0.5 h U 4 h mix & 791 & 1022 & 446 & 576 & 0.32 & 2.64 \\
\hline SnFAU 0.5 h U 4 h mix & 946 & 1236 & 611 & 625 & 0.34 & 2.58 \\
\hline NaBEA commercial & 567 & 715 & 450 & 265 & 0.09 & Absent \\
\hline NaBEA 0.5 h U 4 h mix & 714 & 913 & 389 & 523 & 0.27 & 2.54 \\
\hline SnBEA $0.5 \mathrm{~h}$ U $4 \mathrm{~h}$ mix & 653 & 895 & 485 & 410 & 0.32 & 2.56 \\
\hline
\end{tabular}

* submesopores-pores with sizes $>2 \mathrm{~nm}$.

The pore volume distribution function was calculated using the BJH (Barrett-Joyner-Halenda) algorithm. Except for commercial zeolites, the other synthesized materials display monomodal pore size distribution in mesopore range (insert $1 \mathrm{~A}, \mathrm{~B}-3 \mathrm{~A}, \mathrm{~B}$ in Figures 2 and 3). For the synthesized zeolites we observed large volume of the formed mesopores (increasing from $0.05 \mathrm{~cm}^{3} / \mathrm{g}$ to $0.34 \mathrm{~cm}^{3} / \mathrm{g}$ ). The pore size in the meso range is similar for all the synthesized zeolites and falls within $2.5-2.6 \mathrm{~nm}$ range. The external specific surface area $\left(S_{\text {ext }}\right)$ and micropore specific surface area $\left(S_{\text {micro }}\right)$ were established using the t-plot method. A considerable decrease of micropores proportion in the porous structure of the synthesized materials was observed in comparison with the applied commercial zeolites FAU and BEA with simultaneous significant increase of mesopore specific surface area (external specific surface area $S_{\text {ext }}$ ), which further confirms obtaining additional porosity. 
Photographs taken using scanning electron microscope (SEM), transmission electron microscopy (TEM) and SEM/EDX analysis for the materials modified with tin are presented in Figures 2 and 3. Based on the images from the scanning electron microscopy (SEM), crystallite aggregates of synthesized hierarchical zeolites of nano size were observed. The results of SEM/EDX analysis showed equal distribution of the introduced metal (i.e., tin). The images from the transmission electron microscopy showed the presence of metal nanoparticles on the surface of the materials. Oval-shaped metal nanoparticles, 2-10 nm in size, are gathered in clusters of irregular shape sized from 100 to $300 \mathrm{~nm}$.

Ultraviolet and visible-light (UV-Vis) analysis was conducted to elucidate the coordination environment of tin inside the framework of zeolites. For hierarchical materials, e.g., SnFAU $0.5 \mathrm{~h} \mathrm{U}$ $4 \mathrm{~h}$ mix and SnBEA $0.5 \mathrm{~h} \mathrm{U} 4 \mathrm{~h}$ mix, a broad ultraviolet and visible-light diffuse reflection (DR UV-Vis) peak (Figure 4) appeared around $214 \mathrm{~nm}$ indicating that the tin species are incorporated into the silica pore walls with a tetrahedral coordination $[17,18]$. No bands typical for polymeric $\mathrm{Sn}-\mathrm{O}-\mathrm{Sn}$ type species $(\sim 280 \mathrm{~nm})$ or above $300 \mathrm{~nm}$ indicates that no bulk tin oxide is formed [19]. On the basis of UV-vis spectra it is believed that tin species were incorporated into the framework of all samples studied.

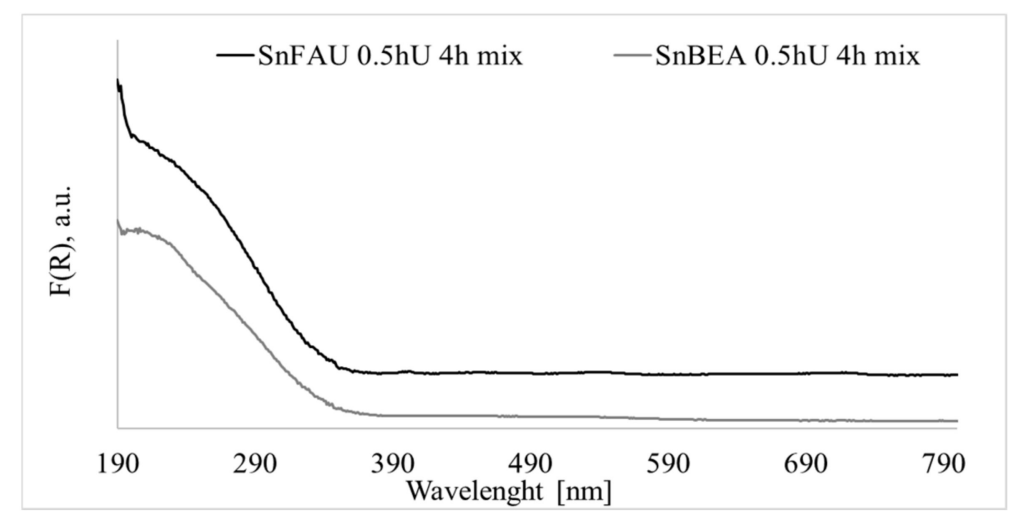

Figure 4. Ultraviolet and visible-light diffuse reflection (DR UV-Vis) spectra of hierarchical materials.

Figure 5 shows the FT-IR (Fourier-transform infrared spectroscopy) spectra in the range of 4000-100 $\mathrm{cm}^{-1}$ (divided into two parts) for the SnFAU $0.5 \mathrm{~h} \mathrm{U} 4 \mathrm{~h}$ mix and SnBEA $0.5 \mathrm{~h} \mathrm{U} 4 \mathrm{~h}$ mix samples. The peak at $960 \mathrm{~cm}^{-1}$ has been ascribed by some authors to the bending vibration of Si-O-M in metal-doped of materials, or this peak was also assigned to the stretching vibration of $\mathrm{Si}-\mathrm{O}_{2}$ of the silanol group [20]. The band at $>3700 \mathrm{~cm}^{-1}$ can be assigned to surface silanol groups, whereas the broad band at $3400-3500 \mathrm{~cm}^{-1}$ was accredited to hydroxyl nests, which consist of a number of silanol groups interacting through extended hydrogen bonding, inside the zeolite mesopores [21,22]. Moreover, one can apply IR spectroscopy to evaluate the strength of the $\mathrm{O}-\mathrm{H}$ bond by the direct measurement of $v(\mathrm{OH})$ stretching frequency. The frequency of $(\mathrm{OH})$ vibrations depends on the electron density in the $\mathrm{OH}$ bond, thus it will shifts towards $3650-3600 \mathrm{~cm}^{-1}$ interval in the case of isolated Brønsted sites [23]. However, a reliable infrared scale for the strength of acidity can only be obtained with the use of probe molecules by carefully monitoring all the perturbations of vibrational features induced by the adsorption of the probe on the Brønsted site. Thus, carrying out the detailed study is necessary and will be the aim of our future work.

The synthesized materials were used in the reaction of dihydroxyacetone (DHA) isomerization to alkyl lactates or to lactic acid. The reaction was conducted using the traditional heating method and microwave radiation.

A credible mechanism of DHA isomerization to lactic acid and alkyl lactates is presented in Figure 6 [22]. 


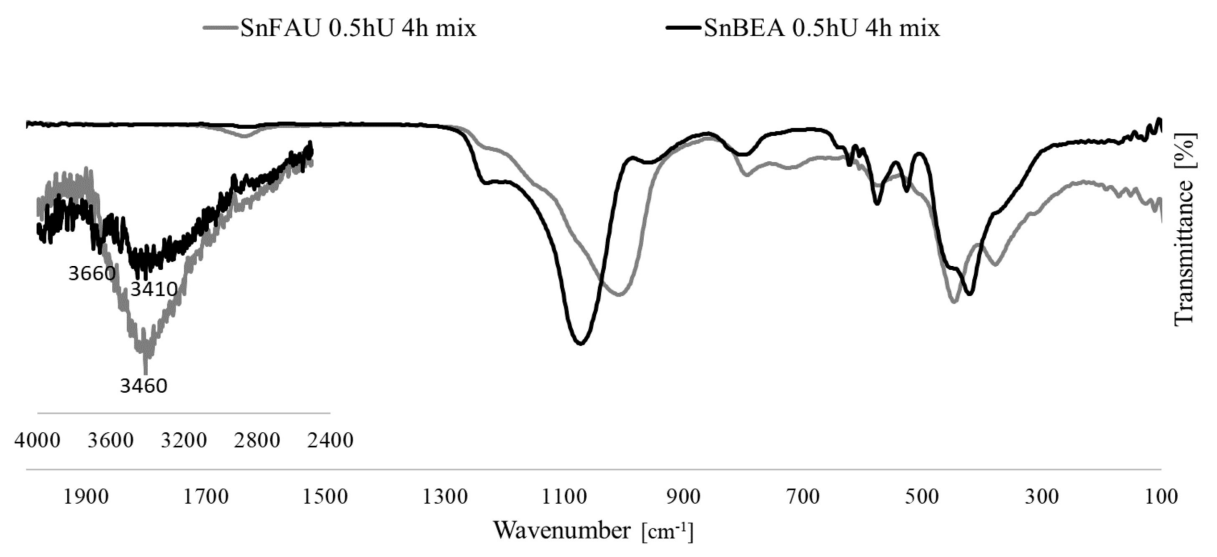

Figure 5. FT-IR spectra of SnFAU $0.5 \mathrm{~h} \mathrm{U} 4 \mathrm{~h}$ and SnBEA $0.5 \mathrm{~h} \mathrm{U} 4 \mathrm{~h}$.

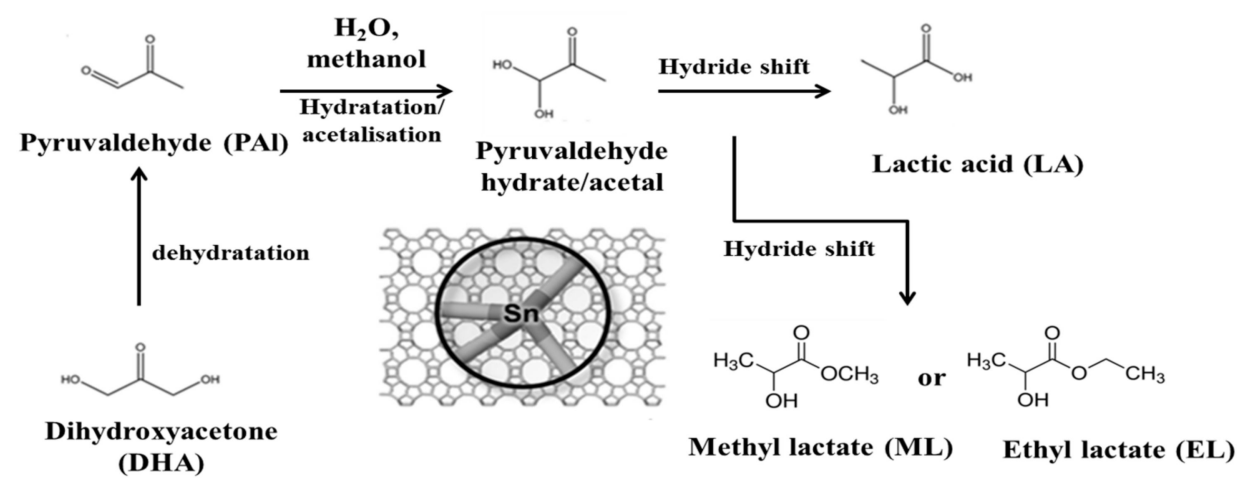

Figure 6. Scheme of triose isomerization reaction to lactic acid (LA) or alkyl lactates-methyl lactate (ML) or ethyl lactate (EL) [22].

It is based on three basic stages. In the first stage, dihydroxyacetone (DHA), as a result of dehydration and regrouping, undergoes transformation to pyruvic aldehyde (PAL). PAL, in turn, is susceptible to nucleophilic attack on aldehyde carbonyl group with water or alcohol. In this way, hydrate or hemiacetal is created. Hemiacetal, in alcohol environment, can react in two ways: by forming dialkylacetal which will contain another alcohol molecule or it can become isomerized to alkyl lactate. In aqueous environment, only isomerization reaction to lactic acid is possible. At the isomerization stage, 1,2 regrouping (transfer) takes place, which occurs as an internal Cannizzaro reaction or as a combination of Meerwein-Ponndorf-Verley reduction reaction and Oppenauer oxidation reaction (MPVO) [24].

The reactions were conducted using the conventional method for $5 \mathrm{~h}$ and the microwave method for $1 \mathrm{~h}$ in alcohol and aqueous environment. In both environments, after $5 \mathrm{~min}$ of conducting the reaction by the conventional method and after $1 \mathrm{~min}$ of applying microwave method, a total decrease of the substrate content in the solution was recorded, which would suggest a $100 \%$ completion of DHA reaction. However, in this time, an appropriate even amount of reaction products were not recorded, whereas a gradual increase in the amount of DHA conversion products was observed.

A rapid sorption (1-5 $\mathrm{min}$ ) of substrate from the solution in the first minutes of the process was observed as well as conversion of the previously adsorbed substrate in the mesopores of the synthesized adsorbents. Moreover, gradual diffusion (within 1-5 h) of conversion products to the solution was noted. The yield to the particular reaction products increased and after maximum time of reaction reached values presented in Table 3. Introduction of tin during the synthesis of the material enabled increase of DHA conversion from 40 to $100 \%$ (see Table 3). High reaction yield to methyl lactate for material SnBEA $0.5 \mathrm{~h} \mathrm{U} 4 \mathrm{~h}$ mix (59\%) and to ethyl lactate (73\%) for material SnFAU $0.5 \mathrm{~h}$ $\mathrm{U} 4 \mathrm{~h}$ mix after $5 \mathrm{~h}$ of conducting the reaction (Table 3, entries 6 and 13). In turn, the application of 
microwave radiation not only caused reduction of the reaction time from $5 \mathrm{~h}$ to $1 \mathrm{~h}$ but also enabled to increase the yields to respective reaction products (Table 3, entries 11-12 and 15-16, Figure 7). In order to select optimal conditions for the reaction, the reaction was conducted on three temperature levels: in room temperature, in 50 and in $80^{\circ} \mathrm{C}$ (Figures 8 and 9). As shown in Table 3, the highest values of DHA conversion were achieved at a temperature of $80^{\circ} \mathrm{C}$, therefore the DHA isomerization reaction in aqueous environment was conducted only in this temperature. In the aqueous environment, for material SnFAU $0.5 \mathrm{~h} \mathrm{U} 4 \mathrm{~h}$ mix 100\% DHA conversion was achieved as well as $92 \%$ yield to lactic acid (Table 3, entry 23). Effect of catalyst recycling in the isomerization of DHA in water catalyzed by SnFAU $0.5 \mathrm{~h} \mathrm{U} 4 \mathrm{~h}$ mix is shown in Table 3 (Table 3, entries 17-21). The catalyst was used in four subsequent runs. The solid recovered was washed four times with water, dried for $5 \mathrm{~h}$ in the oven at $110{ }^{\circ} \mathrm{C}$, calcined at $450{ }^{\circ} \mathrm{C}$ and reused. As can be seen from Table 3, after four runs ( 3 recyclings) there is no loss of activity (conversion was unchanged), while the selectivity to lactic acid seems to benefit to some extent from recycling.

The active sites for the isomerization of DHA in hierarchical zeolites containing tin are Sn atoms. According to the literature, incorporation of tin in silica generates weak Brønsted acidity, providing the catalyst with a higher overall activity $[25,26]$. We can propose in our case that the introduction of tin into hierarchical zeolites generates Lewis acid sites (as tetrahedrally coordinated tin in the silica framework-DR UV-vis study) together with weak Brønsted acidity generated by introducing Sn in the framework or by the formation of hydroxyl nests (due to mesoporores-FTIR study). Further studies are required, especially kinetics and mechanism of the reaction to verify the statement.

Table 3. Catalytic conversion of dihydroxyacetone (DHA) in methanol, ethanol and water using synthesized hierarchical zeolites. The values were calculated in the following manner: Yields $\left(Y_{\mathrm{ML}, \mathrm{EL}, \mathrm{LA}, \mathrm{PAL}}\right)=\mathrm{mol}$ of product $j / \mathrm{mol}$ of DHA at $t=0)$, Conversion DHA $\left(X_{\mathrm{DHA}}\right)=Y_{\mathrm{ML}, \mathrm{EL}, \mathrm{LA}, \mathrm{PAL}} /$ selectivity to product $j$, where $j=$ ML or EL, LA or pyruvic aldehyde (PAL) [27]. Please note that entries 18-20 are catalyst after subsequent recyclings (abbreviation: rec.).

\begin{tabular}{|c|c|c|c|c|c|}
\hline Entry & Catalyst & $X_{\text {DHA }}(\%)$ & $Y_{\mathrm{ML}, \mathrm{EL}, \mathrm{LA}}(\%)$ & $Y_{\mathrm{PAL}}(\%)$ & Time (h) \\
\hline \multicolumn{6}{|c|}{ Catalytic conversion of DHA in Methanol—conventional method of heating $(\mathrm{CM}) 80^{\circ} \mathrm{C}$} \\
\hline 1 & HFAU commercial & 43 & 38 & 5 & 5 \\
\hline 2 & HFAU 0.5 h U 4 h mix & 62 & 45 & 15 & 5 \\
\hline 3 & SnFAU 0.5 h U 4 h mix & 90 & 51 & 39 & 5 \\
\hline 4 & NaBEA commercial & 39 & 35 & 4 & 5 \\
\hline 5 & NaBEA 0.5 h U 4 h mix & 38 & 20 & 18 & 5 \\
\hline 6 & SnBEA 0.5 h U 4 h mix & 84 & 59 & 25 & 5 \\
\hline \multicolumn{6}{|c|}{ Catalytic conversion of DHA in Methanol—conventional method of heating $(\mathrm{CM}) 50^{\circ} \mathrm{C}$} \\
\hline 7 & SnFAU 0.5 h U 4 h mix & 61 & 34 & 27 & 5 \\
\hline 8 & SnBEA $0.5 \mathrm{~h} \mathrm{U} 4 \mathrm{~h}$ mix & 57 & 32 & 25 & 5 \\
\hline \multicolumn{6}{|c|}{ Catalytic conversion of DHA in Methanol—conventional method of heating $(\mathrm{CM}) 25^{\circ} \mathrm{C}$} \\
\hline 9 & SnFAU 0.5 h U 4 h mix & 42 & 22 & 20 & 5 \\
\hline 10 & SnBEA 0.5 h U 4 h mix & 27 & 7 & 20 & 5 \\
\hline \multicolumn{6}{|c|}{ Catalytic conversion of DHA in Methanol-microwave radiation of heating (MR) $80^{\circ} \mathrm{C}$} \\
\hline 11 & SnFAU 0.5 h U 4 h mix & 98 & 82 & 16 & 1 \\
\hline 12 & SnBEA 0.5 h U 4 h mix & 90 & 76 & 14 & 1 \\
\hline \multicolumn{6}{|c|}{ Catalytic conversion of DHA in Ethanol-conventional method of heating $(\mathrm{CM}) 80^{\circ} \mathrm{C}$} \\
\hline 13 & SnFAU 0.5 h U 4 h mix & 93 & 73 & 20 & 5 \\
\hline 14 & SnBEA 0.5 h U 4 h mix & 96 & 58 & 38 & 5 \\
\hline \multicolumn{6}{|c|}{ Catalytic conversion of DHA in Ethanol-microwave radiation of heating (MR) $80^{\circ} \mathrm{C}$} \\
\hline 15 & SnFAU 0.5 h U 4 h mix & 99 & 85 & 14 & 1 \\
\hline
\end{tabular}


Table 3. Cont

\begin{tabular}{|c|c|c|c|c|c|}
\hline Entry & Catalyst & $X_{\text {DHA }}(\%)$ & $Y_{\mathrm{ML}, \mathrm{EL}, \mathrm{LA}}(\%)$ & $Y_{\mathrm{PAL}}(\%)$ & Time (h) \\
\hline 16 & SnBEA 0.5 h U 4 h mix & 98 & 72 & 26 & 1 \\
\hline \multicolumn{6}{|c|}{ Catalytic conversion of DHA in Water-conventional method of heating $(\mathrm{CM}) 80^{\circ} \mathrm{C}$} \\
\hline 17 & SnFAU 0.5 h U 4 h mix & 99 & 89 & 10 & 5 \\
\hline 18 & SnFAU 0.5 h U 4 h mix-1st rec. & 99 & 88 & 11 & 5 \\
\hline 19 & SnFAU 0.5 h U 4 h mix-2nd rec. & 98 & 87 & 12 & 5 \\
\hline 20 & SnFAU 0.5 h U 4 h mix-3rd rec. & 97 & 86 & 12 & 5 \\
\hline 22 & SnBEA 0.5 h U 4 h mix & 99 & 87 & 12 & 5 \\
\hline \multicolumn{6}{|c|}{ Catalytic conversion of DHA in Water-microwave radiation of heating (MR) $80{ }^{\circ} \mathrm{C}$} \\
\hline 23 & SnFAU 0.5 h U 4 h mix & 100 & 92 & 8 & 1 \\
\hline 24 & SnBEA 0.5 h U 4 h mix & 99 & 95 & 4 & 1 \\
\hline
\end{tabular}

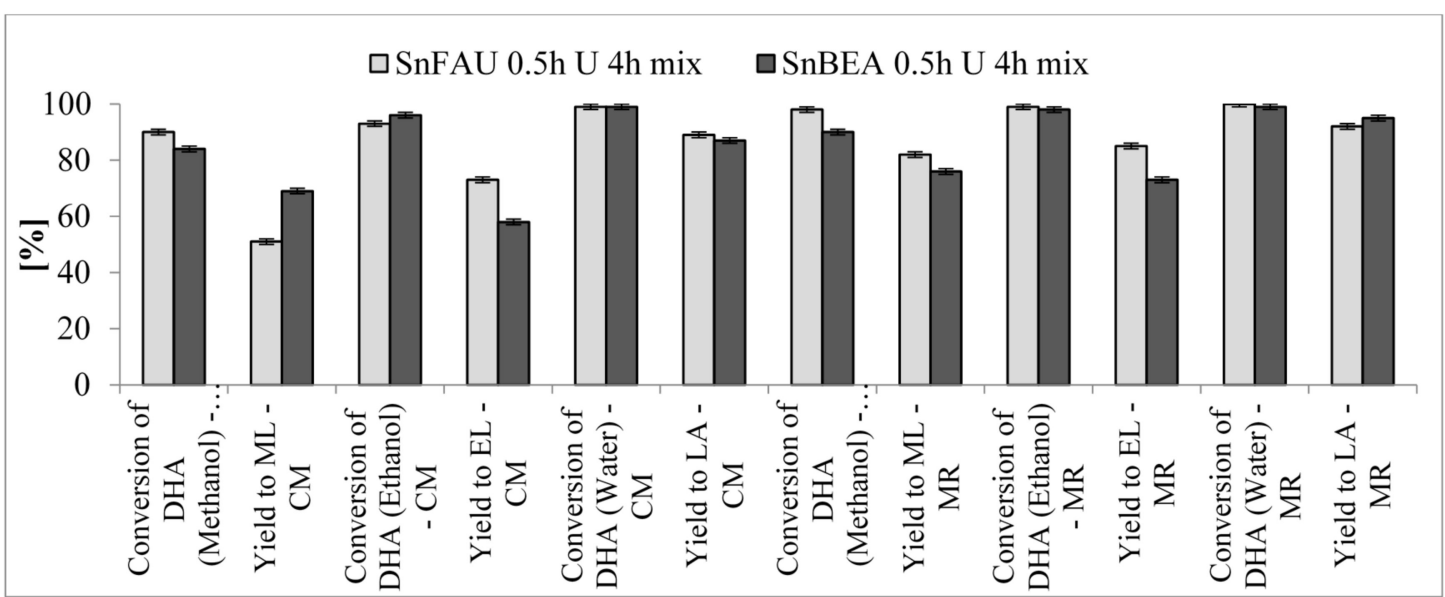

Figure 7. Reaction of DHA isomerization (DHA conversion and conversion yield to the desired reaction product-methyl lactate-ML and ethyl lactate-EL) with the use of SnFAU $0.5 \mathrm{~h} \mathrm{U} 4 \mathrm{~h}$ mix and SnBEA $0.5 \mathrm{~h} \mathrm{U} 4 \mathrm{~h}$ mix - application of conventional heating method and microwave radiation of heating method.

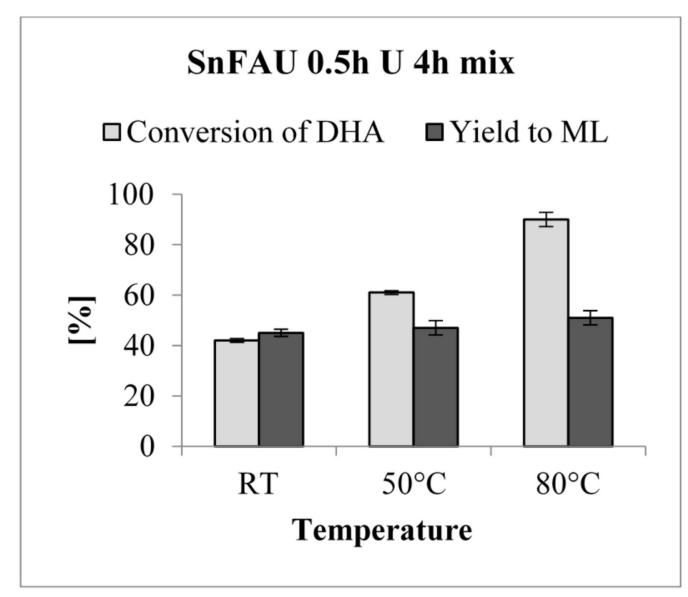

Figure 8. Reaction of DHA isomerization (DHA conversion and conversion yield to the desired reaction product-methyl lactate-ML) with the use of SnFAU $0.5 \mathrm{~h} \mathrm{U} 4 \mathrm{~h}$ mix-application of conventional heating method. 


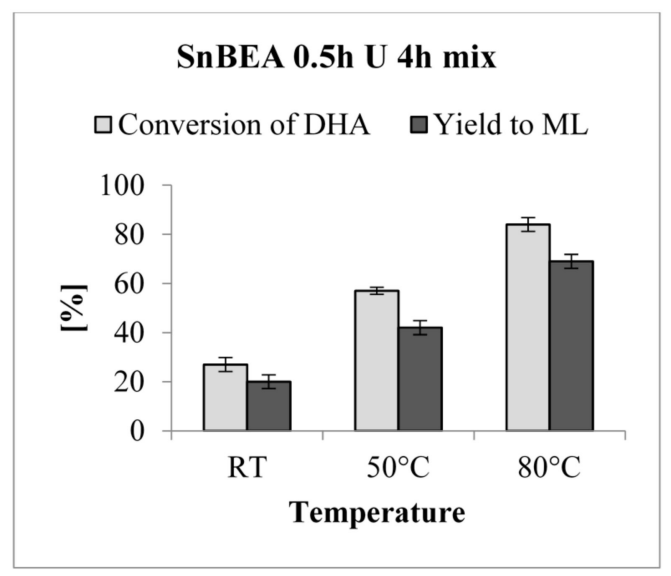

Figure 9. Reaction of DHA isomerization (DHA conversion and conversion yield to the desired reaction product-methyl lactate-ML) with the use of SnBEA $0.5 \mathrm{~h} \mathrm{U} 4 \mathrm{~h}$ mix-application of conventional heating method.

In heterogeneous reactions in liquid phase the theory of microwave-specific effects is that the reaction rates under microwave heating can differ significantly from what is obtained through conventional convectional heating. The main advantage is the ability to selectively heat the catalyst. This method can, under properly designed conditions, selectively heat the catalyst to the temperature required for substrate activation, letting the medium remain at a significantly lower temperature. A possible benefit is that fast activation of the substrate occurs at the hot surface of the catalysts, which also imparts kinetic energy that quickly ejects the product from the hot surface into the cooler medium, thereby impeding further reaction [28].

\section{Materials and Methods}

\subsection{Catalyst Preparation}

$0.5 \mathrm{~g}$ of zeolite FAU or BEA was dispersed in mixture containing $0.35 \mathrm{~g}$ of cetyltrimethylammoniabromide (CTAB, Fluka), $100 \mathrm{~g}$ water, $60 \mathrm{~g}$ ethanol and $1.25 \mathrm{~g}$ ammonia and was treated with ultrasounds for $30 \mathrm{~min}$. Next, $0.56 \mathrm{~g}$ of tetraethyl orthosilicate (TEOS, Aldrich, Steinheim, Germany), $0.029 \mathrm{~g}$ tin source which was tin(IV) chloride (Sigma-Aldrich, Steinheim, Germany) was added and mixed for $4 \mathrm{~h}$. The product obtained was filtered and washed with water-ethanol mixture. The organic template $(\mathrm{CTAB})$ was removed through calcination process in temperature of $550{ }^{\circ} \mathrm{C}$ for $5 \mathrm{~h}$ in air atmosphere.

\subsection{Characteristics of Hierarchical Zeolites}

All the hierarchical zeolites obtained were characterized by using a series of physicochemical techniques.

The structure, morphology and chemical composition of the synthesized materials were determined using scanning electron microscope (SEM, LEO Electron Microscopy Ltd., Thornwood, NY, USA) in combination with an X-ray spectrometer EDX (Quantax 200 with XFlash 4010 detector manufactured by Bruker AXS, Karlsruhe, Germany).

The diffractograms in the low-angle range were made using Bruker AXS D8 Advance apparatus with radiation $\mathrm{CuK} \alpha(\alpha=0.154 \mathrm{~nm})$ in the range of $2 \theta=0.6-8^{\circ} z$ with $0.02^{\circ}$ accuracy.

The low-temperature isotherms of nitrogen adsorption/desorption were made using Micromeritics ASAP 2010 (Micromeritics, Norcross, GA, USA) apparatus in temperature of $77 \mathrm{~K}$ following degasification of the sample in vacuum conditions in temperature of $493 \mathrm{~K}$ for $8 \mathrm{~h}$ until reaching the final pressure of below 0.001 torr. The BET specific surface area was determined by using Braunauer-Emmet-Teller method and Langmuir method. The pore volume was determined 
by using modified BJH algorithm, KJS-BJH method, while the external specific surface area and mesoporous specific surface area by using t-plot method.

The analysis of carbon, hydrogen and nitrogen content in the samples was performed by using Vario Macro CHN elemental analyzer (Elementar Analysensysteme GmbH, Langenselbold, Germany).

DR UV-Vis and FTIR spectroscopies were used to find the location of tin in hierarchical zeolites. Ultraviolet and visible-light diffuse reflection (DR UV-Vis) spectra were recorded on a Varian Carry 300 spectrophotometer by using Praying Mantis DR attachment. The spectra were recorded against a Labsphere certified reflectance standard (99.9\%) for solid samples in the range of 900-190 nm and were recalculated with the Kubelka-Munk equation (denoted as F(R)). The FTIR analysis was made by using an FTIR spectrophotometer (FTIR ATR, Vertex 70, Bruker Optik, Karlsruhe, Germany) equipped with a DLaTGS detector. The analysis was performed after the evacuation of samples at high vacuum for $1 \mathrm{~h}$.

\subsection{Catalytic Tests_DHA Isomerization Reaction to Alkyl Lactates and Lactic Acid}

High performance liquid chromatography (HPLC) method using Varian LC 900 chromatograph with UV-Vis or RI detector and GC equipped with an FID (Varian 3800 Instrument, VF-5 MS Capillary Column, Agilent, Santa Clara, CA, USA) were applied to determine of the reaction products: lactic acid (LA), alkyl lactates (methyl lactate-ML, ethyl lactate-EL), or pyruvic aldehyde (PAL). Reaction of dihydroxyacetone (DHA) isomerization to alkyl lactates and lactic acid was conducted in the following manner: $0.045 \mathrm{~g}$ DHA, $10 \mathrm{~mL}$ of solvent (methanol, ethanol or water) and $0.05 \mathrm{~g}$ of catalyst were placed in reaction dish fitted with magnetic dipole. The optimal temperature and the reaction time using the conventional heating method $(\mathrm{CM})$ were $80^{\circ} \mathrm{C}$ and $5 \mathrm{~h}$, respectively, whereas in the case of microwave radiation heating the respective values were $80^{\circ} \mathrm{C}$ and $1 \mathrm{~h}$. The samples were taken at time interval of 1-360 min.

\section{Conclusions}

In summary, the synthesized hierarchical zeolites containing tin, as micro-mesoporous materials, are capable of an effective (yield $>90 \%$ ) catalytic isomerization of dihydroxyacetone (DHA) to alkyl lactates and lactic acid. Application of microwave radiation contributes to a significant reduction of the catalytic reaction time (from $5 \mathrm{~h}$ to $1 \mathrm{~h}$ ).

Acknowledgments: This work was supported by the National Science Centre, Poland (project FUGA NO.: 2016/20/S/ST4/00547).

Author Contributions: Agnieszka Feliczak-Guzik, Myroslav Sprynskyy, Izabela Nowak and Bogusław Buszewski conceived and designed experiments, analyzed the data, and wrote the manuscript.

Conflicts of Interest: The authors declare no conflict of interest.

\section{References}

1. Malgras, V.; Ji, Q.; Kamachi, Y.; Mori, T.; Shieh, F.K.; Wu, K.C.V.; Ariga, K.; Yamauchi, Y. Templated Synthesis for Nanoarchitectured Porous Materials. Bull. Chem. Soc. Jpn. 2015, 88, 1171-1200. [CrossRef]

2. Dutta, S.; Bhaumik, A.; Wu, K.C.-W. Hierarchically porous carbon derived from polymers and biomass: Effect of interconnected pores on energy applications. Energy Environ. Sci. 2014, 7, 3574-3592. [CrossRef]

3. Shieh, F.K.; Wang, S.C.; Yen, C.I.; Wu, C.C.; Dutta, S.; Chou, L.Y.; Morabito, J.V.; Hu, P.; Hsu, M.H.; Wu, K.C.W.; et al. Imparting functionality to biocatalysts via embedding enzymes into nanoporous materials by a de novo approach: Size-selective sheltering of catalase in metal-organic framework microcrystals. J. Am. Chem. Soc. 2015, 137, 4276-4279. [CrossRef] [PubMed]

4. Shieh, F.K.; Hsiao, C.T.; Kao, H.M.; Sue, Y.C.; Lin, K.W.; Wu, C.C.; Chen, X.C.; Wan, L.; Hsu, M.H.; Hwu, J.R.; et al. Size-adjustable annular ring-functionalized mesoporous silica as effective and selective adsorbents for heavy metal ions. RSC Adv. 2013, 3, 25686-25689. [CrossRef]

5. Chal, R.; Gérardin, C.; Bulut, M.; van Donk, S. Overview and industrial assessment of synthesis strategies towards zeolites with Mesopores. ChemCatChem 2011, 3, 67-81. [CrossRef] 
6. Wei, Y.; Parmentier, T.E.; de Jong, K.P.; Zecevic, J. Tailoring and visualizing the pore architecture of hierarchical zeolites. Chem. Soc. Rev. 2015, 44, 7234-7261. [CrossRef] [PubMed]

7. Perez Ramirez, J.; Christensen, C.H.; Egeblad, K.; Christensen, C.H.; Groen, J.C. Hierarchical Zeolites: enhanced Utilisation of Microporous crystals in catalysis by advances in materials design. Chem. Soc. Rev. 2008, 37, 2530-2542. [CrossRef] [PubMed]

8. Hartmann, M.; Gonche, A.; Schwieger, W. Catalytic test reactions for the evaluation of hierarchical zeolites. Chem. Soc. Rev. 2016, 45, 3313-3330. [CrossRef] [PubMed]

9. Castillo Martinez, F.A.; Balciunas, E.M.; Salgado, J.M.; Domınguez Gonzalez, J.M.; Converti, A.; de Souza Oliveira, R.P. Lactic acid properties, applications and production: A review. Trends Food Sci. Technol. 2013, 30, 70-83. [CrossRef]

10. García-Martínez, J.; Johnson, M.; Valla, J.; Li, K.; Ying, J.Y. Mesostructured zeolite Y—High hydrothermal stability and superior FCC catalytic performance. Catal. Sci. Technol. 2012, 2, 987-994. [CrossRef]

11. Na, J.P.; Liu, G.Z.; Zhou, T.Y.; Ding, G.C.; Hu, S.L.; Wang, L. Synthesis and catalytic performance of ZSM-5/MCM-41 zeolites with varying Mesopore size by surfactant-directed recrystallization. Catal. Lett. 2013, 143, 267-275. [CrossRef]

12. Guo, Y.P.; Wang, H.J.; Guo, Y.J.; Guo, L.H.; Chu, L.F.; Guo, C.X. Fabrication and characterization of hierarchical ZSM-5 zeolites by using organosilanes as additives. Chem. Eng. J. 2011, 166, 391-400. [CrossRef]

13. Wee, Y.J.; Kim, J.N.; Ryu, H.W. Biotechnological production of lactic acid and its recent applications. Food Technol. Biotechnol. 2006, 44, 163-172.

14. Gray, D.R. Morphologic classification of crenulation cleavage. J. Geol. 1977, 85, 229-235. [CrossRef]

15. Müller, J.M.; Mesquita, G.C.; Franco, S.M.; Borges, L.D.; de Macedo, J.L.; Dias, J.A.; Dias, S.C.L. Solid-state dealumination of zeolites for use as catalysts in alcohol dehydration. Microporous Mesoporous Mater. 2015, 204, 50-57. [CrossRef]

16. Bonilla, A.; Baudouin, D.; Pérez-Ramírez, J. Desilication of ferrierite zeolite for porosity generation and improved effectiveness in polyethylene pyrolysis. J. Catal. 2009, 265, 170-180. [CrossRef]

17. Selvaraj, M.; Sinha, P.K. Highly selective and clean synthesis of nopol over well-ordered mesoporous tin silicate catalysts. New J. Chem. 2010, 34, 1921-1929. [CrossRef]

18. Nowak, I.; Feliczak, A.; Nekoksova, I.; Cejka, J. Comparison of oxidation properties of $\mathrm{Nb}$ and $\mathrm{Sn}$ in mesoporous molecular sieves. Appl. Catal. A 2007, 321, 40-62. [CrossRef]

19. Chaudhari, K.; Das, T.K.; Rajmohanan, P.R.; Lazar, K.; Sivasanker, S.; Chandwadkar, A.J. Synthesis, characterization, and catalytic properties of Mesoporous tin-containing analogs of MCM-41. J. Catal. 1999, 183, 281-291. [CrossRef]

20. Casagrande, M.; Storaro, L.; Lenarda, M.; Gersich, J.; Stievano, L.; Wagner, F.E.; Montanari, T. Synthesis and structural characterization of ordered supermicroporous MSU type silica-tin molecular sieves. J. Mater. Chem. 2004, 14, 1010-1016. [CrossRef]

21. Svelle, S.; Sommer, L.; Barbera, K.; Vennestrøm, P.N.R.; Olsbye, U.; Lillerud, K.P.; Bordiga, S.; Pan, Y.-H.; Beato, P. How defects and crystal morphology control the effects of desilication. Catal. Today 2011, 168, 38-47. [CrossRef]

22. Lari, G.M.; García-Muelas, R.; Mondelli, C.; López, N.; Pérez-Ramírez, J. Glyceroloxidehydration to pyruvaldehyde over silver-based catalysts for improved lactic acid production. Green Chem. 2016, 18, 4682-4692. [CrossRef]

23. Bordiga, S.; Lamberti, C.; Bonino, F.; Travertd, A.; Thibault-Starzyk, F. Probing zeolites by vibrational spectroscopies. Chem. Soc. Rev. 2015, 44, 7262-7341. [CrossRef] [PubMed]

24. Serrano, D.P.; Aguado, J.; Morales, G.; Rodriguez, J.M.; Peral, A.; Thommes, M.; Epping, J.P.; Chmelka, B.F. Molecular and meso- and macroscopic properties of hierarchical Nanocrystalline ZSM-5 Zeolite Prepared by Seed Silanization. Chem. Mater. 2009, 21, 641-654. [CrossRef]

25. Li, L.; Stroobants, C.; Lin, K.; Jacobs, P.A.; Sels, B.F.; Pescarmona, P.P. Selective conversion of trioses to lactates over Lewis acid heterogeneous catalysts. Green Chem. 2011, 13, 1175-1181. [CrossRef]

26. De Clippel, F.M.; Dusselier, R.; Van Rompaey, P.; Vanelderen, J.; Dijkmans, E.; Makshina, L.; Giebeler, S.; Oswald, G.V.; Baron, J.F.M.; Denayer, P.P.; et al. Sels, fast and selective sugar conversion to Alkyl Lactate and lactic acid with Bifunctional carbon-silica catalysts. J. Am. Chem. Soc. 2012, 134, 10089-10101. [CrossRef] [PubMed] 
27. Pighin, E.; Díez, V.K.; Di Cosimo, J.I. Kinetic study of the ethyl lactate synthesis from triose sugars on $\mathrm{Sn} / \mathrm{Al}_{2} \mathrm{O}_{3}$ catalysts. Catal. Today 2017, 289, 29-37. [CrossRef]

28. Stiegman, A.E. Loss Mechanisms and Microwave-Specific Effects in Heterogeneous Catalysis, Microwaves in Catalysis: Methodology and Applications, 1st ed.; Wiley-VCH Verlag GmbH \& Co. KGaA: Weinheim, Germany, 2016; pp. 31-47.

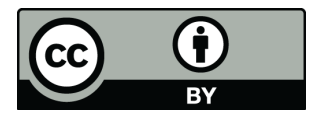

(C) 2018 by the authors. Licensee MDPI, Basel, Switzerland. This article is an open access article distributed under the terms and conditions of the Creative Commons Attribution (CC BY) license (http:/ / creativecommons.org/licenses/by/4.0/). 